\title{
Vitamin D Level in Rheumatic Disease Does it has clinical and immunological significance?
}

\author{
Fatemah A. El-Shabacy ${ }^{1}$, Sherry K. Abd El-Rahman' ${ }^{1}$, Taghred F. Mohamed ${ }^{1}$, \\ Eman Eissa ${ }^{2}$, Eman R. Amer ${ }^{2}$, Sherif Shawaky Elatar ${ }^{3}$ \\ Departments of Rheumatology and Rehabilitation ${ }^{1}$, Clinical Pathology ${ }^{2}$, Benha Teaching Hospital, \\ Internal Medicine ${ }^{3}$, Agouza Rehabilitation Center; Egypt
}

\begin{abstract}
Background: Observational studies in humans suggest an association between vitamin D deficiency and many rheumatologic disorders. Pathophysiological investigations confirm that severe hypovitaminosis D, in genetically predisposed subjects, can impair self tolerance and immune responses by compromising the regulation of dendrite cells, regulatory Tlymphocytes, Th1 cells and B cell function. Objectives: The aim of our work was to assess Vit D level in patients with RA, SLE and Behcet's disease and to evaluate its relation to various parameters of the disease and its activity. Results: Ninety patients (20 RA, 54 SLE and 16 Behcet's disease) were included in this work. They were 42 (46.7\%) males and 48 (53.3\%) females, their age ranged from 20-50 years in males, and 20-45 years in females with mean (44.4 \pm 2.4$)$ years. Twenty apparently healthy person, age and sex matched to the patients were included as a control group. Comparison between the groups of SLE patients, RA patients and controls as regards titer of auto antibodies (LA, RO, SM, anti-DNA, ANA) showed statistically significant differences between SLE patients and both RA patients and controls $(\mathrm{p}<0.001)$. Vitamin D level was found to be lower than normal in all patients groups. It was lower in RA patients 7.62 \pm 1.58 than in SLE 12.81 \pm 1.92 and in Behcet's disease 13.68 \pm 1.99 , comparing vitamin D level in patients and controls showed that it was significantly lower in patients group than controls $(\mathrm{p}<0.001)$.Vitamin D level showed a significant negative correlation with various markers of disease activities of the studied groups, where $\mathrm{p}$ value was $<0.001$ with DAS28 in RA patients and with SLEDIA in SLE patients while it was 0.009 with BDCAF in Behcet's disease. Conclusion: The current study stressed the high prevalence of vitamin D deficiency in patients with autoimmune and inflammatory diseases including RA, SLE and Behcet's disease. Correlation between this defiecincy and indices of disease activity suggest the major role of vitamin D in modulation of immunological etiopathogenesis of these diseases. [Egypt J Rheumatology \& Clinical Immunology, 2015; 3(2): 111-120]
\end{abstract}

Key Words: Vitamin D, RA, SLE.

\section{INTRODUCTION}

The classical, hormonal actions of vitamin D are related to mineral metabolism and skeletal health. Vitamin D enhances intestinal calcium and phosphate absorption, stimulates osteoclast differentiation and calcium reabsorption from bone and promotes mineralization of the bone matrix ${ }^{1}$.

Over the last decade, the perspective on how vitamin $\mathrm{D}$ influences human health has changed dramatically based on the finding that the vitamin $\mathrm{D}$ receptor (VDR) and the vitamin $\mathrm{D}$ activating enzyme 1- $\alpha$-hydroxylase (CYP27B1) are expressed in many cell types which are not involved in bone and mineral metabolism, such as intestine, pancreas, prostate and cells of the immune system. This suggests an important impact of vitamin D on a much wider aspect of human health than previously known. Especially in the field of human immunology, the extra-renal synthesis of the active metabolite calcitriol-1, 25(OH) 2D-by immune cells and peripheral tissues has been proposed to have immunomodulatory properties similar to locally active cytokines ${ }^{2}$. Observational studies in humans suggest an association between vitamin D deficiency and many rheumatologic disorders ${ }^{3}$. Pathophysiological investigations confirm that severe hypovitaminosis $\mathrm{D}$, in genetically predisposed subjects, can impair self tolerance and immune responses by compromising the regulation of dendrite cells, regulatory $\mathrm{T}$ lymphocytes (Tregs), Th1 cells and B cell function $^{4}$. 


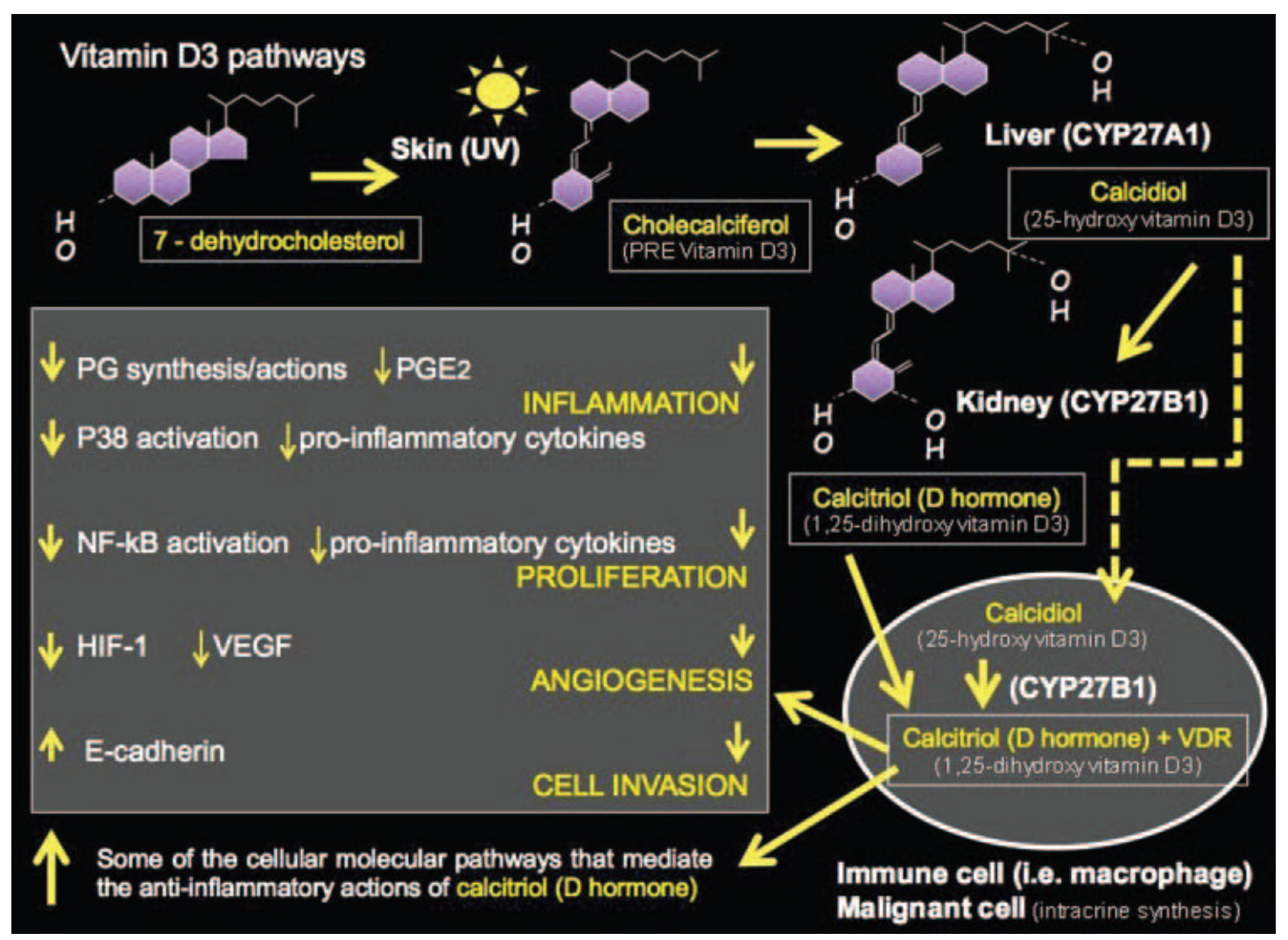

Figure 1. Solid lines indicate direct actions of calcitriol, and dotted lines indicate downstream effects of calcitriol.

\section{Pathways of vitamin D:}

Newly identified target genes for calcitriol (D hormone) reveal multiple molecular pathways of antiinflammatory actions for 1, 25(OH) D3 in several cell types. These include: inhibition of prostaglandin (PG) synthesis and biological actions; inhibition of p38 stress kinas activation and production of proinflammatory cytokines such as IL-6 (via induction of MAP kinas phosphatase 5 (MKP5 expression); inhibition of nuclear factor $\kappa \mathrm{B}(\mathrm{NF}-\kappa \mathrm{B})$ signaling which results in the attenuation of the synthesis of proinflammatory cytokines such as interleukin-8 (IL8) (via up-regulation of the expression of insulin-like growth factor binding protein-3 (IGFBP-3); inhibition of angiogenesis due to suppressive effects on the expression of proangiogenic factors such as hypoxiainducible factor 1 (HIF-1) and vascular endothelial growth factor; increase in the expression of Ecadherin, leading to the inhibition of invasion and metastasis $^{5}$. Cross-sectional studies have shown that deficient serum levels of vitamin D $(25(\mathrm{OH}) \mathrm{D})(<20$ $\mathrm{ng} / \mathrm{ml}$ ) are present in a significant percentage, not only in patients with autoimmune diseases such as multiple sclerosis (MS), type 1 diabetes, systemic lupus erythematosus (SLE) or rheumatoid arthritis (RA), but also in healthy subjects. In addition, the presence of severe $25(\mathrm{OH})$ D deficiency $(<10 \mathrm{ng} / \mathrm{ml})$ is also involved in the generation of symptoms that characterize patients with rheumatic diseases (ie, musculoskeletal pain in RA), and supplementation seems to induce improvements ${ }^{6}$. In our study we assessed vitamin D levels and its relations to many clinical and laboratory aspects in some rheumatic diseases such as RA, SLE and Behcet's disease.

\section{PATIENTS AND METHODS}

This study was carried out on Ninety patients recruited from outpatient clinic and inpatient wards of rheumatology department Benha teaching hospital. They were twenty RA patients, diagnosed according to EULAR/ ACR revised criteria ${ }^{7}$, fifty four SLE patients according to Systemic Lupus International 
Collaborating Clinics classification (SLICC) criteria $^{8}$ and the remaining sixteen patients was Behcet's disease, diagnosed according to ACR criteria ${ }^{9}$. Twenty apparently healthy person age and sex matched to the patients were included as a control group. The ninety patients were $42(46.7 \%)$ males and 48 (53.3\%) females, their age ranged from 20-50 years in males, and 20-45 years in females with mean (44.4 2.4 ) years.

\section{Inclusion criteria:}

1. Patients aged $>18$ years old.

2. Non pregnant non lactating females.

3. Able to give written informed consent after explanation of all procedures, risks and benefits of the study.

\section{Exclusion criteria:}

1. Patients with other autoimmune or inflammatory disease.

2. Overlap syndrome.

3. Patients with other co- morbidity (hepatic or renal).

\section{All patients were subjected to:}

- Thorough clinical examination.

- Disease activity assessment using DAS28 for $\mathrm{RA}^{10}$, SLE disease activity index (SLEDAI) for $\mathrm{SLE}^{11}$ and BDCAF for Behcet's disease ${ }^{12}$.

- Laboratory investigations including:

- erythrocyte sedimentation rate (ESR), quantitative $\mathrm{C}$ - reactive protein (CRP). 25-OH-vitamin D was measured by ELISA method; by commercially available kit from WKEA (Med, supplies) USA.

\section{Principle of the assay.}

A purified human 25-OH-D antibody coat micro titer plate well; to make solid phase antibody, then 25$\mathrm{OH}$ was added to the wells. Combined 25-OH-D which with enzyme labeled, became antibody-antigenenzyme-antibody complex.

After washing completely, substrate was added, substrate became blue color.HRP enzyme catalyzed reaction was terminated by the addition of a sulphuric acid solution and the color change was measured spectrophotometrically at a wave length of $450 \mathrm{~nm}$. The concentration of 25-OH-D in the sample is then determined by comparing the O.D. of the sample to the standard curve ${ }^{13,14}$.

ANA, ds DNA, Smith (sm), SS-A (RO), SSB (La) antibodies assay

ANA, ds DNA, Smith (sm), SS-A (RO), SSB (La) were measured by Enzyme linked immunosorbent assay (ELISA), by a commercially available kit from Trinity from Blotech.
Principle of the test:

Purified antigen, ANA, ds DNA, Smith (sm), SS-A (RO), SSB (La) are bound to microwells. Washing of the micro wells removes unbound serum antibodies. Horseradish perooxidase (HRP) conjugated $\mathrm{IgG}$ immunologically binds to the bound patient antibodies forming a (conjugate antibody antigen sandwich).Washing of the microwells remove unbound conjugate hydrolyser to form a blue color. An addition of acid stops the reaction forming a yellow end product. The intensity of the color is measured photometrically.

The concentration of antibody in the sample is then determined by comparing the O.D. of the sample to the standard curve ${ }^{15-17}$.

\section{Statistical Analysis:}

The collected data were tabulated and analyzed using SPSS version 16 soft ware (Spss Inc, Chicago, ILL Company). Categorical data were presented as number and percentages while continuous data were expressed as mean \pm standard deviation. Chi square rest $\left(\mathrm{X}^{2}\right)$, Fisher's exact test, Student "t" test, ANOVA (F) test Pearson's correlation coefficient ( $r$ ) were used as tests of significance. Significant ANOVA was followed by post hoc multiple comparisons using Bonferroni test to detect significant pairs. The accepted level of significance in this work was stated at 0.05 ( $\mathrm{P} \leq 0.05$ was considered significant).

\section{RESULTS}

Ninety patients (20 RA, 54 SLE and 16 Behcet's disease) were included in this work (Figure $2)$. They were $42(46.7 \%)$ males and $48(53.3 \%)$ females, their age ranged from $20-50$ years in males, and 20-45 years in females with mean $(44.4 \pm 2.4)$ years. Twenty apparently healthy person age and sex matched to the patients were included as a control group. Estimation of auto antibodies in RA and SLE patients group showed that ANA and anti DNA antibodies were positive in all SLE cases (100\%), while both were negative in RA cases. Anti SM anti bodies were positive in ten SLE patients (18.5\%) but, negative in all RA patients. Anti Ro was positive in eight RA (40\%) and in ten SLE patients (18.5\%) while anti La was positive in forty six SLE patients (80\%) and negative in all RA patients (Table 1). Comparison between the groups of SLE patients, RA patients and controls as regards titer of auto antibodies (LA, RO, SM, anti-DNA, ANA) showed statistically significant differences between SLE patients and both RA patients and controls $(\mathrm{p}<0.001)$ (Table $2 \&$ Figure 3). 
* Assessment of vitamin D level:

Vitamin D level was found to be lower than normal in all patients groups. It was lower in RA patients $(7.62 \pm 1.58)$ than in SLE $(12.81 \pm 1.92)$ and in Behcet's disease (13.68 \pm 1.99$)$ (Table 3). Comparing vitamin $\mathrm{D}$ level in patients and controls showed that it was significantly lower in patients group than controls $(\mathrm{p}<0.001)$ (Table $4 \&$ Figure 4$)$.

Vitamin D level showed a significant negative correlation with various markers of disease activities of the studied groups, where $\mathrm{p}$ value was $<0.001$ with DAS28 in RA patients and with SLEDIA in SLE patients while it was 0.009 with BDCAF in Behcet's disease (Table $5 \&$ Figure 5). Decrements in Vitamin D levels increased with higher disease activity scores where it was lower in SLE patients with moderate than mild SLEDAI scores $(11.75 \pm 0.937$ versus $14.93 \pm 1.613)(\mathrm{p}<0.001) \quad($ Table 6). Behcet's disease patients were presented with a variety of clinical presentations including oral and genital ulcers, arthritis and uveitis. The lowest level of vitamin D was estimated in patients presented with oral ulcers and uveitis (Table 6), despite that comparison between patients with and without uveitis regarding level of vitamin D showed no significant difference (Table 7).

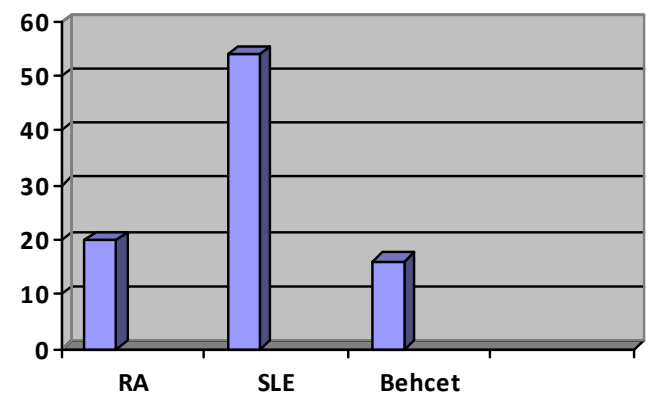

Figure 2. Distribution of rheumatic diseases among patients group.

Table 1. Prevalence of auto antibodies among studied groups.

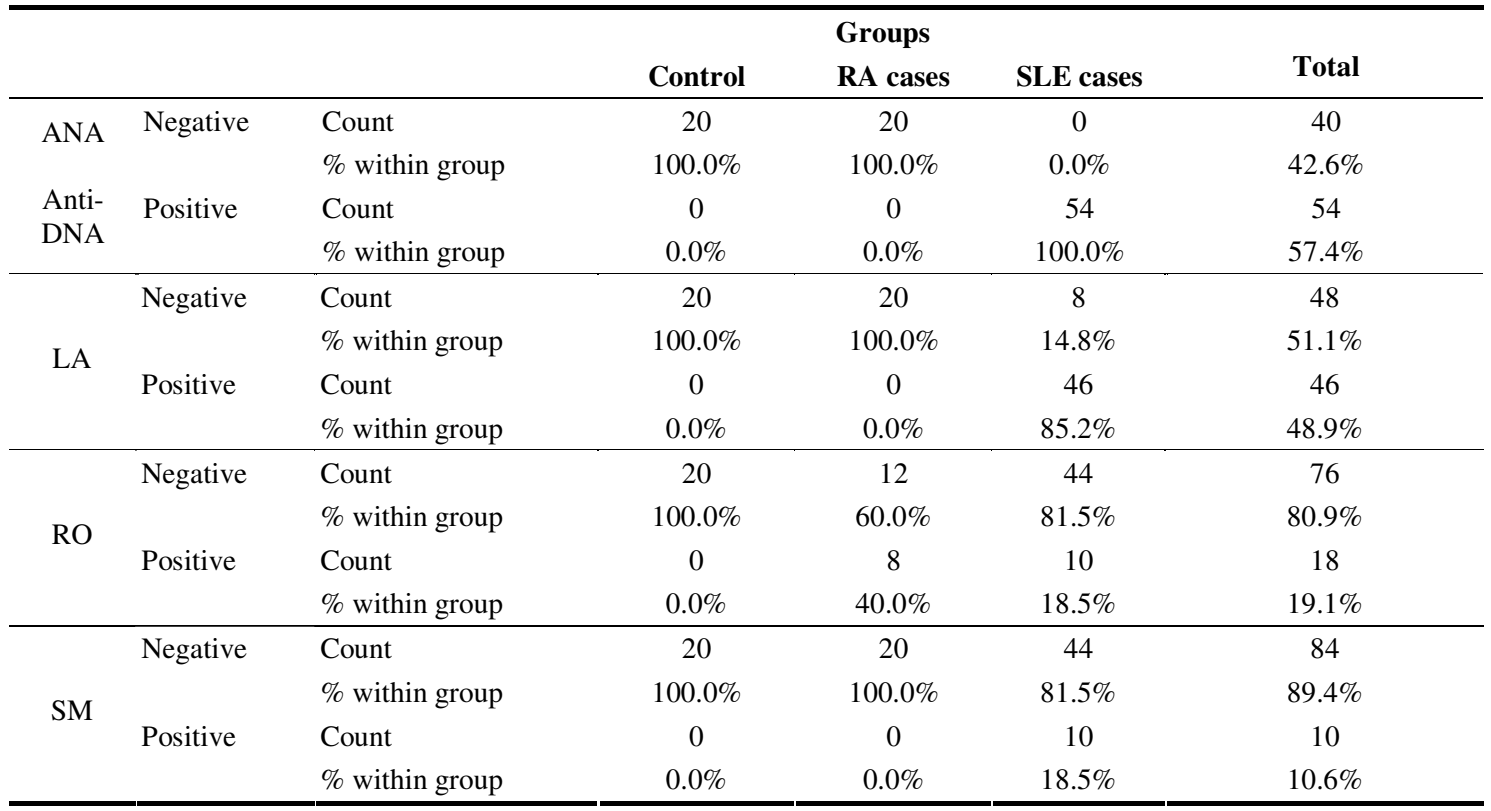


Table 2. Comparison of some of the studied groups regarding the auto antibodies levels.

\begin{tabular}{|c|c|c|c|c|c|c|c|c|}
\hline \multirow[t]{2}{*}{ Variable } & \multicolumn{2}{|c|}{$\begin{array}{c}\text { Controls } \\
(\mathbf{n}=20)\end{array}$} & \multicolumn{2}{|c|}{$\begin{array}{c}\text { RA cases } \\
(n=20)\end{array}$} & \multicolumn{2}{|c|}{$\begin{array}{c}\text { SLE cases } \\
(n=54)\end{array}$} & \multirow[t]{2}{*}{ F test } & \multirow[t]{2}{*}{$\mathbf{P}$} \\
\hline & Mean & $\pm \mathrm{SD}$ & Mean & \pm SD & Mean & $\pm \mathrm{SD}$ & & \\
\hline LA titer & 0.12 & 0.030 & 0.116 & 0.029 & $1.197 * \dagger$ & 0.355 & 180.7 & $<0.001$ (HS) \\
\hline RO titer & 0.65 & 0.139 & $0.98^{*}$ & 0.380 & $0.74 \ddagger$ & 0.214 & 10.4 & $<0.001$ (HS) \\
\hline SM titer & 0.16 & 0.032 & $0.45^{*}$ & 0.098 & $0.72 * \dagger$ & 0.296 & 44.4 & $<0.001$ (HS) \\
\hline Anti DNA titer & 0.53 & 0.133 & $0.77 *$ & 0.187 & $1.55^{*} \dagger$ & 0.263 & 187.02 & $<0.001$ (HS) \\
\hline ANA titer & 0.81 & 0.052 & 0.72 & 0.116 & $1.63 * \dagger$ & 0.410 & 84.9 & $<0.001$ (HS) \\
\hline
\end{tabular}

$* \rightarrow$ significant in comparison with controls

$\dagger \rightarrow$ significant in comparison with RA cases

All post hoc multiple comparisons were performed using Bonferroni test.

(LA, RO, SM, Anti-DNA, ANA level are $\leq 1$ this mean negative).

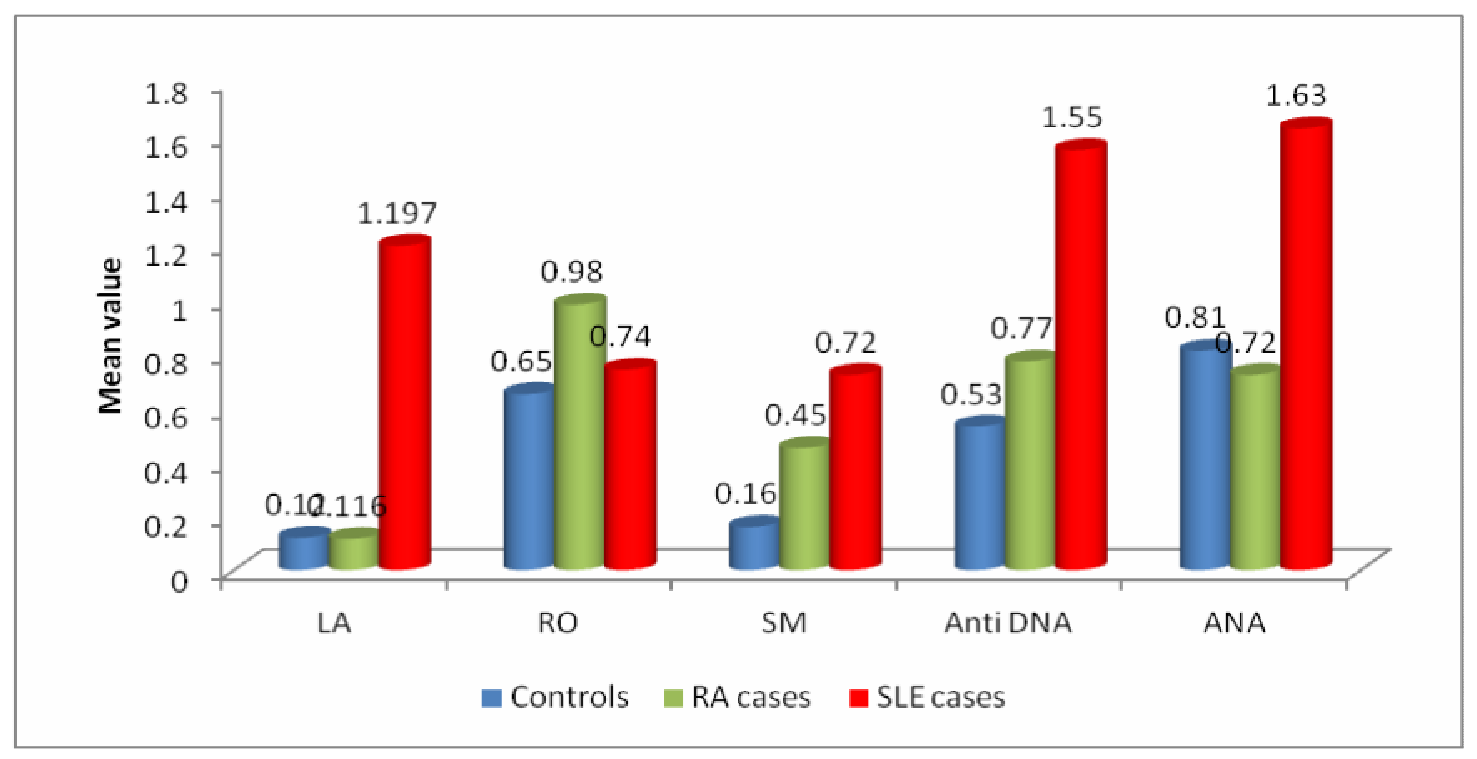

Figure 3. Comparison of some of the studied groups regarding the auto antibodies levels.

Table 3. Comparing the studied groups regarding vitamin D levels.

\begin{tabular}{|c|c|c|c|c|c|c|c|}
\hline & & & \multicolumn{4}{|c|}{ Group } & \multirow{2}{*}{ Total } \\
\hline & & & Controls & Behecet' cases & RA cases & SLE cases & \\
\hline \multirow{4}{*}{ 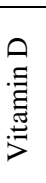 } & \multirow{2}{*}{ Below normal } & Count & 0 & 16 & 20 & 54 & 90 \\
\hline & & $\%$ within group & $0.0 \%$ & $100.0 \%$ & $100.0 \%$ & $100.0 \%$ & $81.8 \%$ \\
\hline & \multirow{2}{*}{ Normal } & Count & 20 & 0 & 0 & 0 & 20 \\
\hline & & $\%$ within group & $100.0 \%$ & $0.0 \%$ & $0.0 \%$ & $0.0 \%$ & $18.2 \%$ \\
\hline & \multirow{2}{*}{ Total } & Count & 20 & 16 & 20 & 54 & 110 \\
\hline & & $\%$ within group & $100.0 \%$ & $100.0 \%$ & $100.0 \%$ & $100.0 \%$ & $100.0 \%$ \\
\hline
\end{tabular}


Table 4. Comparing mean levels of vitamin D among the studied groups.

\begin{tabular}{lccccc}
\hline \multirow{2}{*}{ Group } & n. & \multicolumn{2}{c}{ Vitamin D } & ANOVA & P \\
\cline { 3 - 5 } & & Mean & $\mathbf{\pm}$ SD & 237.6 & $<0.001$ \\
\hline Controls & 20 & 25.53 & 3.428 & & (HS) \\
Behest' cases & 16 & $13.68^{* \dagger}$ & 1.997 & & \\
RA cases & 20 & $7.62^{*}$ & 1.581 & & \\
SLE cases & 54 & $12.81^{* \dagger}$ & 1.922 & & \\
\hline
\end{tabular}

$*$ significant in comparison with controls

$\dagger \rightarrow$ significant in comparison with RA cases

All post hoc multiple comparisons were performed using Bonferroni test.

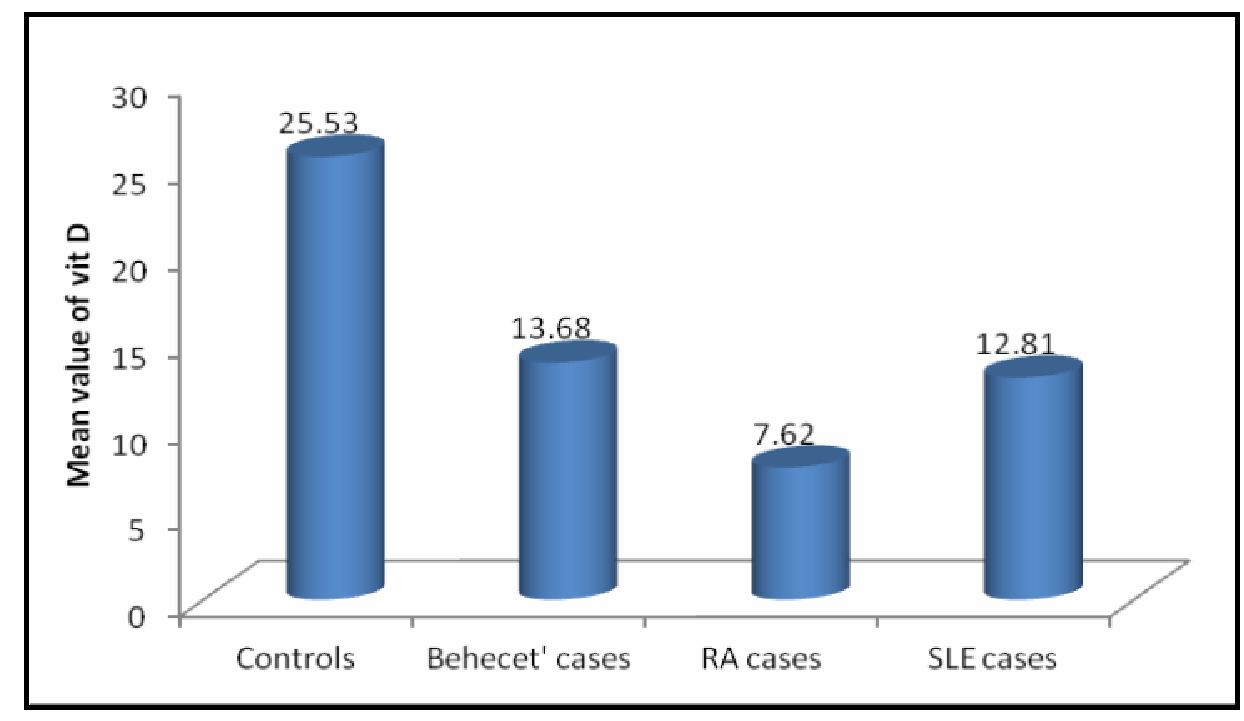

Figure 4. Comparing mean levels of vitamin D among the studied groups.

Table 5. Correlation between vitamin D levels and disease activity scores among the studied patients.

\begin{tabular}{|c|c|c|c|c|c|}
\hline \multirow{3}{*}{ With } & \multicolumn{5}{|c|}{ Vitamin D } \\
\hline & \multirow[t]{2}{*}{ Behcet's $(n=16)$} & \multicolumn{2}{|c|}{$R A$ cases $(n=20)$} & \multicolumn{2}{|c|}{ SLE cases $(n=54)$} \\
\hline & & $\mathbf{R}$ & $\mathbf{P}$ & $\mathbf{r}$ & $\mathbf{P}$ \\
\hline DAS & & -0.762 & $<0.001(\mathrm{HS})$ & ----- & ----- \\
\hline SLEDAI change & & -------- & ------ & -0.552 & $<0.001(\mathrm{HS})$ \\
\hline BDCAF & $0.009(\mathrm{~S})$ & ------- & ------ & -------- & ----- \\
\hline
\end{tabular}

Table 6. Comparison of Vitamin D levels in SLE patients with mild and moderate SLEDAI.

\begin{tabular}{|c|c|c|c|c|c|}
\hline \multirow{2}{*}{ SLEDAI } & \multirow{2}{*}{ n. } & \multicolumn{2}{|c|}{ Vitamin D } & \multirow{2}{*}{ St " $t$ " } & \multirow{2}{*}{$\mathbf{P}$} \\
\hline & & Mean & \pm SD & & \\
\hline Mild & 18 & 14.93 & 1.613 & \multirow{2}{*}{9.15} & \multirow{2}{*}{$\begin{array}{c}<0.001 \\
\text { (HS) }\end{array}$} \\
\hline Moderate & 36 & 11.75 & 0.937 & & \\
\hline
\end{tabular}



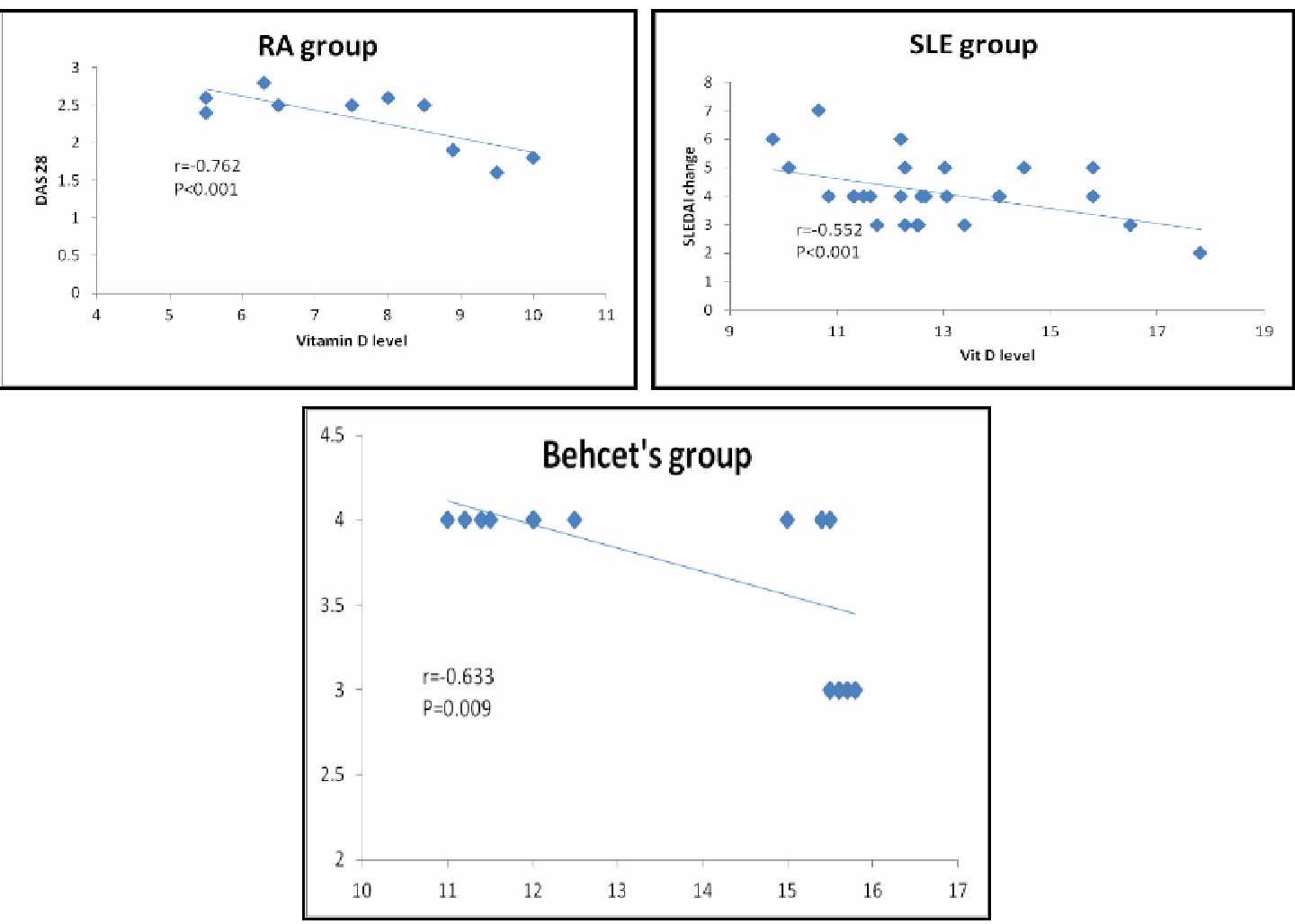

Figure 5. Correlation between Vitamin D levels and various scores of disease activity of the studied groups.

Table 7. Behcet's disease patients with different clinical presentations and Vitamin levels.

\begin{tabular}{|c|c|c|c|c|c|c|}
\hline \multirow{2}{*}{ Clinical picture } & \multirow{2}{*}{$\mathbf{N}$} & \multicolumn{2}{|c|}{ Vitamin D } & \multirow{2}{*}{$\mathbf{F}$ test } & \multirow{2}{*}{$\mathbf{P}$} & \multirow{2}{*}{$\begin{array}{c}\text { Post hoc } \\
\text { multiple } \\
\text { comparison }\end{array}$} \\
\hline & & Mean & S.D & & & \\
\hline oral ulcer, uveitis (I) & 4 & 11.27 & 0.221 & \multirow{4}{*}{450.7} & \multirow{4}{*}{$<0.001(\mathrm{HS})$} & $\mathrm{I} \neq \mathrm{II}$ \\
\hline oral, genital ulcer, arthritis (II) & 4 & 12.13 & 0.243 & & & $\begin{array}{l}\mathrm{I} \neq \mathrm{III} \\
\mathrm{I} \neq \mathrm{IV}\end{array}$ \\
\hline oral, uveitis, arthritis (III) & 4 & 15.32 & 0.221 & & & $\begin{array}{l}\mathrm{II} \neq \mathrm{IIII} \\
\mathrm{II} \neq \mathrm{IV}\end{array}$ \\
\hline Oral ulcer, arthritis (IV) & 4 & 15.65 & 0.129 & & & \\
\hline
\end{tabular}

Table 8. Comparison between Behcet disease patients with and without uveitis regarding Vitamin D levels.

\begin{tabular}{llcccc}
\hline \multirow{2}{*}{ Uveitis } & N & \multicolumn{2}{c}{ Vitamin D level } & \multirow{2}{*}{ St.”'” } & P \\
\cline { 3 - 4 } & & Mean & Std. Deviation & & \\
\hline No & 8 & 13.71 & 1.80 & 0.05 & 0.95 (NS) \\
Yes & 8 & 13.65 & 2.29 & & \\
\hline
\end{tabular}




\section{DISCUSSION}

Autoimmune diseases are characterized by a loss of immune homeostasis resulting in corrupted selfantigen recognition followed by the destruction of body tissue by autoreactive immune cells. A combination of genetic predisposition, epidemiological risk factors and environmental contributors contributes to the development of autoimmune diseases. One important factor may be the availability of sufficient vitamin D levels as various epidemiological studies suggest associations between vitamin $\mathrm{D}$ deficiency and a higher incidence of autoimmune diseases, such as, systemic lupus erythematosus (SLE), rheumatoid arthritis (RA) and Behcet's disease ${ }^{18}$.

The aim of our work was to assess Vit D level in patients with RA, SLE and Behcet's disease and to evaluate its relation to various parameters of the disease and its activity.

This work found that Vit D level was lower in RA patients than control, with significant negative correlation with disease activity index (DAS28). These results coincide with Rajeev et al., who stated that Serum vitamin D levels were significantly low in RA patients than in healthy controls. Vitamin D deficiency was seen in significantly higher numbers of patients and vitamin $\mathrm{D}$ had negative correlation with disease activity ${ }^{19}$. Similar results were also reported by another study where, the researchers suggested that vitamin D supplementation may be needed not only for the prevention of osteoporosis but also, for pain relief in patients with $\mathrm{RA}^{20}$.

The proposed explanation of these result was that Vitamin D has immunoregulatory activity and vitamin D receptors are present in a number of cells of the immune system. Immunomodulation is mediated via vitamin $\mathrm{D}$ receptor (VDR) present on antigen presenting cell, activated $\mathrm{T}$ lymphocyte and activated B lymphocyte. Vitamin D leads to induction of regulatory $\mathrm{T}$ cell and $\mathrm{NK} \mathrm{T}$ cell while vitamin $\mathrm{D}$ inhibits TH1 cell response so vitamin D suppresses experimental autoimmunity. As RA is one of the TH1 cell mediated disorder so vitamin D deficiency or insufficiency may be one of the several environmental causes leading to development of RA ${ }^{19}$.

On the other hand Rossini et al., reported that vitamin D deficiency is equally common in RA and healthy controls ${ }^{21}$, similar result also, observed by Turhanoglu et al 22 .

Vit D level estimated in SLE patients was lower than its level in controls, also, it was significantly negatively correlated with disease activity index (SLEDAI). Vitamin D level was lower in patients with moderate than mild disease activity index.
In agreement with these results Borba et al., stated that Vit D levels were lower in SLE patients than controls which was related to the SLEDAI, so, they concluded that SLE patients demonstrated changes in bone remodeling strongly related to disease activity. A high prevalence of $25 \mathrm{OHD}$ deficiency was observed in SLE patients, indicating the need for vitamin $\mathrm{D}$ replacement ${ }^{23}$. Recently, a study conducted by Northcott and his collagues supported the results of the current study, they reported that in patients with SLE, low vitamin D was associated with a higher disease activity and an increase in serum vitamin D was associated with reduced disease activity over time. They recommended that the therapeutic effect of vitamin D in SLE should be further assessed in interventional studies ${ }^{24}$.

SLE is a chronic multisystem inflammatory autoimmune disease that is characterised by immunological abnormalities resulting in the production of autoantibodies. The steps leading to autoimmune-mediated inflammation are believed to be stimulated by the uptake of nucleic acid-containing immune complexes by plasmacytoid dendritic cells, and the resulting activation of Type I interferon expression. This inflammatory milieu promotes defective function of regulatory $\mathrm{T}$ cells (Tregs) and hyperactivity of helper $\mathrm{T}$ cells (Th cells), and the survival and activation of autoreactive $\mathrm{B}$ cells that produce autoantibodies ${ }^{25}$.

There is increasing evidence to suggest that vitamin D impacts negatively on many of these events. This includes vitamin D-induced downregulation of the Th1 immune response and of the proliferation of activated B cells, while upregulating Tregs . A recent study showed that vitamin D3 inhibits dendritic cell maturation and expression of IFN- $\alpha$ induced genes in SLE patients ${ }^{25}$.

Low concentration of vitamin D in SLE patients is not surprising mainly because SLE patients often have risk factor of low vitamin D level such as the use of long- term sunscreen, lack of dietary intake , and the use of full covered clothing. SLE patients tend to avoid the sun because of photosensitive rashes and potential of disease flare .It is also, known that the SLE patients produce anti - vitamin D antibodies ${ }^{26}$.

However, in contrast to this $\mathrm{Kim}$ and his coworkers failed to show any correlation between Vit D level and disease activity in SLE patients ${ }^{27}$.

A small sample of Behcet's disease patients was included in this study. Assessment of Vit D level among them showed that it was lower than controls with statistical negative correlation with disease activity sacore BDCAF . Similarly, a study conducted by Eyedeh and his associates stated that serum 25hydroxyvitamin D levels were decreased in patients 
with Behcet's Disease ${ }^{28}$. Hamzaoui and Hamzaoui who focused on the peripheral immune system Th1, Th2, Th17 and Treg cells and vitamin D level in their works, speculated that this hormone is not an immunosuppressive agent, but rather an immune regulatory agent. The beneficial effects of vitamin D in autoimmunity include the induction of tolerogenic dendritic cells, which includes the downregulation of costimulatory molecules, a decreased IL-12 secretion and increased IL-10 secretion in antigen presenting cells(APCs), and the ability of these APCs to induce Treg rather than effector $\mathrm{T}$ cells. Vitamin $\mathrm{D}$ can also directly promote the development and function of Treg in vitro ${ }^{29}$.

Other researches reported that stimulation of naive $\mathrm{CD} 4[+] \mathrm{T}$ cells under Th17 polarising conditions showed a higher Th17 cell differentiation in active Behcet's disease patients. The addition of vitamin D significantly inhibited Th17 cell differentiation both in Behcet's disease and in normal controls $^{30}$.

Can and his collagues who agreed with the current study reported that vitamin D deficiency is associated with disease activity, endothelial function and carotid intima media thickness in patients with Behcet's disease. A high presence of vitamin D deficiency was observed in Behcet's disease patients, and replacement of vitamin D had favourable effects on endothelial function ${ }^{31}$.

Behcet's disease patients included in this study were classified into four groups as regards their clinical manifestations, copmarison between these groups regarding vitamin $\mathrm{D}$ levels showed statistically significant differences between them ,but copmarison between patients presented with and without uveitis , as regards vitamin D level was not statistically significant. These results didn't coincide with the study of Rose and coworkers who stated that vitamin D inhibited the Th17 response that is responsible for the occular inflammation, influencing $\mathrm{T}$ cell cytokine production and the priming ability of dendritic cells These studies provide evidence that vitamin $\mathrm{D}$ supplementation could be beneficial not only during the active inflammatory condition but also for prevention of uveitis as well ${ }^{32}$.

Controversy between both studies may be explained by the small sample of Behcet's disease included in this study in contrast to Rose et al.

Finally, the pathogenesis of vitamin D deficiency is not clearly understood. Several factors, such as impaired calcium and vitamin D intake, malnutrition, smoking, alcohol consumption, inadequate sunlight exposure, hypogonadism, aging, corticosteroid therapy, and impaired physical activity, may play an important roles in the etiopathogenesis of vitamin D deficiency. Increased metabolism or impaired 25-hydroxylation induced by medication or by disease involvement may affect vitamin $\mathrm{D}$ values. In addition, the inhibition of $1-\alpha$-hydroxylase by TNF- $\alpha$ may contribute to lower vitamin D levels ${ }^{28}$.

In conclusion, the current study stressed the high prevalence of vitamin D deficiency in patients with autoimmune and inflammatory diseases including RA, SLE and Behcet's disease . Correlation between this defiecincy and indices of disease activity suggest the major role of vitamin $\mathrm{D}$ in modulation of immunological etiopathogenesis of these diseases. Addition of vitamin D supplementations in combination with other lines of management of these diseases is recommended.

\section{REFERENGES}

1. Bouillon R., Carmeliet G., Verlinden L.et al. Vitamin D and human health: Lessons from vitamin D receptor null mice. Endocr. Rev. 2008; 29:726-776. doi: 10.1210/er.2008-0004.

2. Barbara Prietl, Gerlies T, Thomas R et al. Biological effect of vitamin D Nutrients $2013 \mathrm{Jul}$; 5(7): 2502-2521.

3. Ayah M. Boudal and Suzan M. Attar. Vitamin D and Autoimmune Disease, Insights and Perspectives in Rheumatology, Dr. Andrew Harrison (Ed.) 2012, ISBN; 978-953-307-846-5.

4. Cutolo M, Plebani M, Shoenfeld Y, et al. Vitamin $\mathrm{D}$ endocrine system and the immune response in rheumatic diseases. Vitam Horm 2011 ;86:327-5.

5. Maurizio Cutolo. Further emergent evidence for the vitamin $\mathrm{D}$ endocrine system involvement in autoimmune rheumatic disease risk and prognosis. Ann Rheum Dis 2013 April Vol 72 No 4.

6. Gopinath K, Danda D et al. Supplementation of 1,25 dihydroxy vitamin D3 in patients with treatment naive early rheumatoid arthritis: a randomized controlled trial. Int $\mathrm{J}$ Rheum Dis 2011;14:332-9.

7. Aletaha D. , Neogi T., Silman A . J., Funovits J. et al. 2010 rheumatoid arthritis classification criteria: an American College of Rheumatology/European League Against Rheumatism collaborative initiative study . Ann. Rheum . Dis. 2010 ; 69(9):1580-8.

8. Michet petri, Ana-Maria Orba, Graciela S, et al. Derivation and validation of the Systemic Lupus International Collaborating Clinics classification (SLICC) criteria for systemic lupus erythematosus. Arthritis \& Rheumatism. 2012 Volume 64, Issue 8, pages 2677-2686.

9. International Team for the Revision of the International Criteria for Behcet's Disease. Evaluation of the International Criteria for Behcet's disease (ICBD) Clinical and Experimental Rheumatology.2006; 24(supplement 42):p. S13. 
10. Prevoo M.L, Van't Hof et al. Modified disease activity scores that include twenty -eight joints counts. Arthritis. Rheum.1995; 38:44-48.

11. Bombardier $\mathrm{C}$ et al. the committee on prognosis studies in SLE disease activity index(SLEDAI).Arthritis and Rheum1992;35:62530

12. Bhakta BB, Brennan P, James TE, Chamberlin MA, Noble BA, Silman AJ. Behcet's disease; evaluation of new instrument to measure clinical activity.Rheumatology.1999;38:728-33.

13. Venazi,W.E, Arroyo, R,A the ANA by Hep-2 cell line Assay in a Normal population. In Arthritis and Rheumatism, Abstracts of scientific presentions,1994 Regional Meeting of the American college of rheumatogy, 1994, 37(6), Abstract\#6FP. Data on file. HD-0043-797-F.

14. CDC-NIH Manual .Biosafety in microbiological and biomedical laboraties, $3^{\text {rd }}$ Edation . U.S.Dept.of Health and Human Services,public Health service.1993; PP9-12.

15. Rubin, R,L. 1992.Enzyme- linked immunosorbent Assay for Anti-DNA and Antihistone Antibodies including Anti - (H2A-H2B). In manual of clinical laboratory immunology $\quad$.N.R.Rose,et al.,eds. $4^{\text {th }}$ Edition . 108:735-740

16. NCCLS. National committee for clinical laboratory standard Preparation and testing of reagent water in the clinical laboratory. NCCLS Publication1997 C3-A3.

17. NCCLS. National committee for clinical laboratory standard. internal quality control testing: Principles and definition. NCCLS Publication 1991 C24-3.

18. Barbara Priet 1, Gerlies Treiber, et al. Vitamin D and Immune Function Nutrients. 2013 Jul; 5(7): 2502-2521.

19. Rajeev Sharma, Renu Saigal, Laxmikant Goyal et al. Estimation of Vitamin D Levels in Rheumatoid Arthritis Patients and its Correlation with the Disease Activity Journal of the association of physicians of india $2014 \cdot$ vol 62 .

20. Lisa Emrich. Vitamin D Deficiency Associated with Disease Activity in RA. Health guide 2012February; 40:455-9.

21. Rossini M, Maddali Bongi S, La Montagna G.et al. Vitamin D deficiency in rheumatoid arthritis: prevalence, determinants and associations with disease activity and disability. Arthritis Research and Therapy 2010; 12:R216.

22. Turhanoglu AD, Guler H, Yonden $\mathrm{Z}$ et al. The relationship betweenvitamin $\mathrm{D}$ and disease activity and functional health status in rheumatoid arthritis. Rheumatol Int 2009; 10:1393-6.

23. Borba V. Z. C. ,. Vieira J. G. H , KasamatsuT et al. Vitamin D deficiency in patients with active systemic lupus erythematosus Osteoporos Int 2009 ; 20:427-433.

24. Northcott M, Hoi A B-Y, Morand EF and Nikpour M. Association of low vitamin D with high disease activity in systemic lupus erythematosus. Lupus Sci Med 2015; 2: e000064 doi:10.1136.

25. Yap KS, Northcott M, Hoi AB-Y,et al. Lupus Science \& Medicine 20152 :e000064

26 Kusworini Handono, Leny Puspitasari et al. Vitamin D Serum Level And Disease Activity In Patients With Systemic Lupus Erythematosus.International Journal of Pharmaceutical Science Invention 2013;51:140-5.

27. Kim H A, Sung J M, Yoon J M, et al. Vitamin D may not be a Good Marker of Disease Activity in Korean Patients with Systemic Lupus Erythematosus. Rheumatol Int $2010 ; 11: 152-5$.

28. Eyedeh Tahereh Faezi, Narges Ansari, et al. Vitamin D deficiency in patients with Behcet's disease Journal of Diabetes \& Metabolic Disorders $2014 ; 13: 12-6$

29. Hamzaoui K, Hamzaoui A. Vitamin D level and potential impact on immune cells in Behçet's disease. OA Inflammation 2013 Jun 01; 1(1):6

30. Tian Y, Wang C, Ye Z, Xiao X, et al. Effect of 1,25-dihydroxyvitamin D3 on Th17 and Th1 response in patients with Behçet's disease. Invest Ophthalmol Vis Sci 2012 Sep;53(10):6434-41.

31. Can M, Gunes M, Haliloglu OA, et al. Effect of vitamin $\mathrm{D}$ deficiency and replacement on endothelial functions in Behçet's disease. Clin Exp Rheumatol 2012;30(3 Suppl 72):S57-61.

32. Rose Y. Reins, A et al. Vitamin D: Implications for ocular disease and therapeutic potential. Experimental Eye Research 2015 ; 1-10. 